\title{
Distribution and plant availability of heavy metals in different particle-size fractions of soil
}

\author{
Jin Qian ${ }^{\mathrm{a}}$, Xiao-quan Shan*a ${ }^{*}$ Zi-jian Wang ${ }^{\mathrm{b}}$, Qiang $\mathrm{Tu}^{\mathrm{a}}$ \\ ${ }^{a}$ Research Center for Eco-Environmental Sciences, Academia Sinica, P.O. Box 2871, Beijing 100085, China \\ bState Key Laboratory of Environmental Aquatic Chemistry, P.O. Box 2871, Beijing 100085, China
}

Received 10 January 1996; accepted 25 March 1996

\begin{abstract}
The distribution of heavy metals and their availability to plants were studied with respect to the particle-size fractions of soil. Soil samples with a range of chemical and physical properties were collected from 10 different rural regions of China. Extractable heavy metals $(\mathrm{Ni}, \mathrm{Co}, \mathrm{Cu}$ and $\mathrm{Pb}$ ) in the soils using different extractants are compared with the metal contents in winter wheat (Triticum aestivum L.) and alfalfa (Medicago sativa L.) grown on the soils in a greenhouse study. Correlation analysis showed that $0.1 \mathrm{M} \mathrm{HCl}$ gave the best estimate of plant-available $\mathrm{Ni}$ and $\mathrm{Co}$, while DTPA was most suitable for $\mathrm{Cu}$ and $\mathrm{Pb}$. Seven of the soils were partitioned into five particle-size fractions: coarse sand $(>500 \mu \mathrm{m})$, medium sand $(125-500 \mu \mathrm{m})$, fine sand $(50-125 \mu \mathrm{m})$, silt $(2-50 \mu \mathrm{m})$, and clay $(<2 \mu \mathrm{m})$. The metals were characteristically enriched in the clay and one of the sand fractions. Extraction studies on each size fraction indicated that fine sand gave a large amount of extractable $\mathrm{Ni}, \mathrm{Cu}$, and $\mathrm{Pb}$ and medium sand gave high extractable contents of $\mathrm{Co}$. The extractable amounts of $\mathrm{Co}$ and $\mathrm{Pb}$ were also high in the clay fraction. With regard to the relative contribution of different size fractions, silt was found to be the major fraction responsible for metal availability, primarily due to its abundance in all the soil samples. For $\mathrm{Ni}, \mathrm{Cu}$, and $\mathrm{Pb}$, clay and fine sand fractions also had a significant influence on metal availability. For $\mathrm{Co}$, after the silt fraction, the dominant fraction responsible for its availability was clay followed by the medium sand fraction. From the soil textural data and extraction data of each size fraction, it was possible to infer the relative importance of the fractions with respect to their contribution to metal availability.
\end{abstract}

Keywords: Heavy metals; Soils; Particle-size fractions; Plant availability

\section{Introduction}

Increased heavy metal concentrations in the soil (mostly from anthropogenic activities such as sewage sludge application) are considered to pose possibly serious hazards in the soil-plant-animal

\footnotetext{
* Corresponding author.
}

system. Potential danger from metal accumulation by plants grown on such soil is becoming an increasing problem in many countries. This has created a demand for an intensive research effort aimed at predicting the availability of heavy metals in the soil environment (Sterritt and Lester, 1980; Arendt et al., 1990; Nriagu, 1991).

Besides plant species, the availability of metals 
to plants will depend on their chemical speciation and is determined by the physical and chemical properties of the soil, such as soil particle-size distribution, organic matter content, cation exchange capacity, salinity, $\mathrm{pH}$ and redox potential (Soon and Bates, 1982; Sauerbeck and Hein, 1991; Davies, 1992). These factors are not completely understood, and simple relationships are seldom found in natural soil systems between plant metal levels and total metal concentrations in soils (Iyengar et al., 1981; Sims and Kline, 1991). Proper appreciation of the effect of heavy metals in soil on plants can only be attained from a precise knowledge of heavy metal speciation and the response of the plants to each species (Sterritt and Lester, 1980; Cottenie, 1981).

A number of methods have been proposed for the evaluation of plant uptake of heavy metals in the soil. Generally, chemical fractionation has become a common operational approach to bridge the relationship between the bioavailable fraction of a metal in soil and its content in plants (Haq et al., 1980; Lake and Lester, 1984; Sauerbeck and Hein, 1991). A wide variety of extractants, such as weak acids, neutral salts, and chelating acids, have been used to extract plant available metals (Martens, 1968, Lindsay and Norvell, 1978; Haq et al., 1980; Mehlich, 1984; Singh and Narwal, 1984). Although these methods are subject to analytical limitations, such studies continue to receive considerable attention. However, many of them are so condition-specific because the effectiveness of the extractants for removing plant available metals varies with plant species, soil type, the extractant used and the metal concerned. Also, knowledge gained from previous correlation studies by a given extractant may or may not be valid under different soil conditions (Singh and Narwal, 1984; Taylor et al., 1993). So far there is no absolutely reliable method of determining metal availability to plants, and a blank adoption of them without proper assessment may not be advisable. It is apparent that more refined interpretation of soil properties is required to further characterize heavy metals. It would therefore be more meaningful if a wider range of soil-specific factors can be taken into account.

Significant effects of the particle-size distribution on the concentrations of heavy metals in soils have been reported (Tiller, 1958; Förstner, 1980; Haque and Subramanian, 1982). From the particle-size fractions - sand, silt, and clay - the finer particles show higher concentration of heavy metals due to increased surface areas, higher clay minerals and organic matter content, and the presence of Fe-Mn oxide phases (Förstner, 1980; Haque and Subramanian, 1982). However, most frequently metal availability from the different size fractions of soil has been neglected. In contrast to the great amount of work on extractable heavy metals in soil samples and their uptake to plants, little is known about the relationships between

Table 1

Selected chemical and physical properties of the soils used in the pot experiments and laboratory studies

\begin{tabular}{cllllll}
\hline Sample & $\begin{array}{l}\text { Geographical } \\
\text { origin }\end{array}$ & Order & Family & $\mathrm{pH}$ & $\begin{array}{l}\text { CEC } \\
(\text { mequiv. } / \\
100 \mathrm{~g})\end{array}$ & $\begin{array}{l}\text { Organic } \\
\text { matter } \\
(\% \mathrm{w} / \mathrm{w})\end{array}$ \\
\hline 1 & Linyi & Entisol & Silty-clay, mixed & 7.59 & 25.8 & 2.06 \\
2 & Liaocheng & Alfisol & Sandy-silty, mixed & 7.93 & 19.9 & 2.92 \\
3 & Mudanjiang & Mollisol & Sandy-silty, mixed & 6.47 & 20.7 & 7.47 \\
4 & Qinghe & Mollisol & Sandy-silty, mixed & 7.91 & 22.7 & 6.45 \\
5 & Hangzhou & Ultisol & Fine-silty, mixed & 5.51 & 14.6 & 7.09 \\
6 & Changsha & Ultisol & Sandy-silty, mixed & 6.78 & 14.2 & 5.16 \\
7 & Changchun & Mollisol & Sandy-silty, mixed & 7.60 & 14.3 & 5.42 \\
8 & Nanjing & Alfisol & Fine-silty, mixed & 7.87 & 10.1 & 4.24 \\
9 & Bajia & Mollisol & Fine-silty, mixed & 8.03 & 11.8 & 5.06 \\
10 & Miaopu & Mollisol & Fine-silty, mixed & 8.11 & 11.7 & 3.04 \\
\hline
\end{tabular}


Table 2

Extractants and procedure used for the evaluation of metal extractability from soil

\begin{tabular}{|c|c|c|c|}
\hline Extractant & Composition & $\begin{array}{l}\text { Soil/ex- } \\
\text { tractant } \\
\text { ratio }\end{array}$ & $\begin{array}{l}\text { Shaking } \\
\text { time }\end{array}$ \\
\hline DTPA & $\begin{array}{l}0.005 \mathrm{M} \mathrm{DTPA}+0.01 \mathrm{M} \mathrm{CaCl}_{2}+0.1 \mathrm{M} \text { TEA (Triethanolamine) adjusted to } \mathrm{pH} 7.3 \\
\text { with } 1 \mathrm{M} \mathrm{HCl}\end{array}$ & $1 / 2$ & $2 \mathrm{~h}$ \\
\hline $0.1 \mathrm{M} \mathrm{HCl}$ & $0.1 \mathrm{M} \mathrm{HCl}$ & $1 / 10$ & $1 \mathrm{~h}$ \\
\hline Mehlich 3 & $\begin{array}{l}0.2 \mathrm{M} \mathrm{CH}_{3} \mathrm{COOH}+0.25 \mathrm{M} \mathrm{NH}_{4} \mathrm{NO}_{3}+0.015 \mathrm{M} \mathrm{NH}_{4} \mathrm{~F}+0.013 \mathrm{M} \mathrm{HNO}_{3}+0.001 \mathrm{M} \\
\text { EDTA }\end{array}$ & $1 / 10$ & $5 \mathrm{~min}$ \\
\hline
\end{tabular}

plant availability of heavy metals and their extractable concentrations in different particle-size fractions.

In the present study, both total and extractable concentrations of heavy metals in the particle-size fractions of soil were examined to assess their availability to cultivated winter wheat (Triticum aestivum $\mathrm{L}$.) and alfalfa (Medicago sativa $\mathrm{L}$.). The aim of this paper was to examine the distribution and extractability of heavy metals in various particle-size fractions of soil and to investigate interactions between the extractable metals and soil texture with respect to plant uptake of the metals.

\section{Materials and methods}

\subsection{Soil characterisation}

The soil samples used in this study were collected from 10 different rural regions of China, representing a range of chemical and physical properties. They are all from cultivated soils and the samples were taken from the surface layer (0-20 $\mathrm{cm})$. The soils were air-dried, ground, and passed through a 2-mm screen to remove rocks, roots, and other large particles. Precautions were taken to avoid contamination during sampling, drying, grinding, and storage. For the laboratory analyses a representative $4-\mathrm{kg}$ subsample of each soil was used for characterisation, chemical fractionation, and preparation for a pot-culture experiment designed to determine the plant availability of trace metals.

Soil description is according to the American Classification System. Soil pH was measured in deionized water using a 1:1 (w:v) soil/solution ratio. After $1 \mathrm{~h}$ of equilibration, organic matter was determined by the Walkley-Black procedure (Nelson and Sommers, 1982). Cation exchange capacity (CEC) was determined by the method described by Rhoades (1982). Selected properties of the soils are presented in Table 1.

\subsection{Extraction procedure}

Since the relationship between plant metal concentrations and soil extractable metals varies with plant species and the range of types and amounts of clays, oxides, and organic matter found in soils, no single extractant can provide a reliable prediction of plant-available metals for different soilplant systems.

In this study, the soils were individually extracted with the following extractants which generally gave better results in previous investigations.

1. DTPA (diethylenetriaminepentaacetic acid) (Lindsay and Norvell, 1978).

2. $0.1 \mathrm{M} \mathrm{HCl}$ (Martens, 1968).

3. Mehlich 3 (Mehlich, 1984).

The composition of the extractants, soil/extractant ratio and shaking time are listed in Table 2. Extractions were performed with $1.00 \mathrm{~g}$ of dried soil sample in $50 \mathrm{ml}$ polypropylene centrifuge tubes with mechanical shaking. All extractions were made with triplicate samples from the same site. The triplicate analyses varied from their means by no more than $10 \%$, so the average results were used for further analysis.

Total metal content in soils was determined by dissolving $0.200 \mathrm{~g}$ of dried soil with $3 \mathrm{ml}$ of $\mathrm{HNO}_{3}$-HF-HClO ${ }_{4}$ mixture followed by elemental 
Table 3

Total metal content in the 10 soil samples under investigation

\begin{tabular}{llc}
\hline Metal & \multicolumn{2}{l}{ Concentration $\left(\mu \mathrm{g} \mathrm{g}^{-1} \text { dry wt. }\right)^{\mathrm{a}}$} \\
\cline { 2 - 3 } & Range & Mean \\
\hline $\mathrm{Ni}$ & $2.61-16.5$ & 9.78 \\
$\mathrm{Co}$ & $1.04-17.2$ & 7.40 \\
$\mathrm{Cu}$ & $3.93-46.9$ & 17.2 \\
$\mathrm{~Pb}$ & $6.57-67.5$ & 29.4 \\
\hline
\end{tabular}

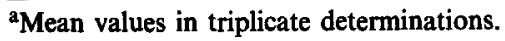

analysis. Total contents for $\mathrm{Ni}, \mathrm{Co}, \mathrm{Cu}$, and $\mathrm{Pb}$ in the investigated soils are listed in Table 3.

\subsection{Particle-size fractionation}

The soil samples were partitioned into five size fractions: coarse sand (>500 $\mu \mathrm{m})$, medium sand $(125-500 \mu \mathrm{m})$, fine sand $(50-125 \mu \mathrm{m})$, silt $(2-50$ $\mu \mathrm{m})$, and clay $(<2 \mu \mathrm{m})$. The separation was based on Stoke's Law. The samples were dispersed in distilled-deionized water by means of a supersonic wave of $19 \mathrm{kHz}, 100 \mathrm{~W}$, and $30 \mathrm{~W} / \mathrm{cm}^{2}$. No breakage of particles by supersonic treatment was observed. The tiiree sand fractions were separated by wet-sieving with nylon sieves. Particles $<50$ $\mu \mathrm{m}$ were thoroughly washed through the sieve until the percolating water was clear. This suspension was separated into silt and clay by repeated

Table 4

Distribution of size fractions separated from seven soil samples (\% soil dry wt.)

\begin{tabular}{llllll}
\hline Sample & \multicolumn{5}{l}{ Particle-size fraction } \\
\cline { 2 - 6 } No. & \begin{tabular}{l}
\multicolumn{5}{l}{} \\
Coarse
\end{tabular} & \multicolumn{1}{l}{ Medium } & Fine & Silt & Clay \\
& sand & sand & sand & $(2-50$ & $(<2 \mu \mathrm{m})$ \\
& $(>500$ & $(125-500$ & $(50-125$ & $\mu \mathrm{m})$ & \\
& $\mu \mathrm{m})$ & $\mu \mathrm{m})$ & $\mu \mathrm{m})$ & & \\
\hline 1 & 1.84 & 2.03 & 1.88 & 74.65 & 19.59 \\
2 & 19.64 & 9.35 & 6.32 & 51.59 & 13.09 \\
3 & 9.16 & 14.21 & 8.73 & 56.10 & 11.81 \\
4 & 1.15 & 3.37 & 15.78 & 57.31 & 22.38 \\
5 & 1.70 & 2.41 & 8.69 & 75.20 & 12.01 \\
6 & 1.03 & 0.84 & 3.12 & 51.71 & 43.29 \\
7 & 8.99 & 14.15 & 14.33 & 53.64 & 8.90 \\
\hline
\end{tabular}

sedimentation/decanting cycles. No dispersing agents or inorganic salts were added during these separation procedures. After collection, the size fractions were dried at $60^{\circ} \mathrm{C}$, weighed, and stored for further analysis. All particle-size fractionations were carried out in duplicate. The coefficients of variations of duplicate determinations were $<5 \%$.

The particle-size separations were performed for soil samples 1-7 because not enough samples from the other three soils could be collected in the separation procedure. The distribution of the particlesize fractions of the investigated soils is summarized in Table 4.

Similar to the extracting procedure described above, each particle-size fraction was extracted by DTPA and $0.1 \mathrm{M} \mathrm{HCl}$ to determine the extractable metal concentrations and by $\mathrm{HNO}_{3}-\mathrm{HF}-\mathrm{HClO}_{4}$ to determine the total metal content. All extractions were made in duplicate.

\subsection{Pot-culture experiment}

The experimental plants were winter wheat (Triticum aestivum L.) and alfalfa (Medicago sativa L.). The air-dried soil samples were placed in plastic-lined pots $(1000 \mathrm{~g} / \mathrm{pot})$ and seeds sown under greenhouse conditions. Triplicate samples were made at the same time. Winter wheat and alfalfa were sown at 15 and 30 seeds per pot and subsequently thinned to 12 and 20 plants per pot, respectively. The pots received supplemental fertilizer with a $\mathrm{NH}_{4} \mathrm{NO}_{3}-\mathrm{KH}_{2} \mathrm{PO}_{4}$ solution supplying $10,10,13 \mathrm{mg} /$ pot of elemental $\mathrm{N}, \mathrm{P}$ and $\mathrm{K}$, respectively. The soils were initially adjusted to approximately $60 \%$ water-holding capacity, and losses from evapotranspiration were made up by daily watering with deionized water.

The plants were harvested 40 days after planting. Winter wheat and alfalfa were sampled as a whole by a plastic knife. The harvested samples were washed with deionized water, dried at $60^{\circ} \mathrm{C}$ for $48 \mathrm{~h}$ and ground in an agate mortar and pestle to pass a $0.85-\mathrm{mm}(20 \mathrm{mesh})$ sieve. Plant analysis for $\mathrm{Ni}, \mathrm{Co}, \mathrm{Cu}$ and $\mathrm{Pb}$ was accomplished by digesting a portion of dried, ground sample $(0.500$ g) in a 3:1 mixture of $\mathrm{HNO}_{3}$ and $\mathrm{HClO}_{4}(5 \mathrm{ml})$. The analyses were carried out in triplicate. 
Table 5

Analytical results $(\mu \mathrm{g} / \mathrm{g})$ of certified reference materials by ICP-AES or GF-AAS ( \pm standard deviation of five determinations)

\begin{tabular}{|c|c|c|c|c|c|c|}
\hline \multirow[t]{3}{*}{ Element } & \multicolumn{6}{|l|}{ Sample } \\
\hline & \multicolumn{2}{|l|}{ GBW07403 } & \multicolumn{2}{|l|}{ GBW07404 } & \multicolumn{2}{|l|}{ GBW07408 } \\
\hline & Average & Certified & Average & Certified & Average & Certified \\
\hline $\mathrm{Ni}$ & $13.1 \pm 2.3$ & $12.2 \pm 1.9$ & $61.7 \pm 7.0$ & $64.2 \pm 6.8$ & $31.8 \pm 2.9$ & $31.5 \pm 2.7$ \\
\hline Co & $5.1 \pm 1.5$ & $5.5 \pm 1.0$ & $20.6 \pm 3.6$ & $22.3 \pm 2.5$ & $11.0 \pm 2.4$ & $12.7 \pm 1.7$ \\
\hline $\mathrm{Cu}$ & $13.6 \pm 3.0$ & $11.4 \pm 1.6$ & $44.7 \pm 4.8$ & $40.5 \pm 3.5$ & $26.2 \pm 2.3$ & $24.3 \pm 1.8$ \\
\hline $\mathrm{Pb}$ & $23.7 \pm 5.3$ & $26 \pm 4$ & $61.4 \pm 9.2$ & $58.5 \pm 7.1$ & $21.1 \pm 4.5$ & $21 \pm 3$ \\
\hline
\end{tabular}

\subsection{Elemental analysis}

The contents of $\mathrm{Ni}, \mathrm{Co}, \mathrm{Cu}$ and $\mathrm{Pb}$ were determined by inductively coupled plasma-optical emission spectroscopy (Jarrell-Ash Model 1155V) or by atomic absorption spectrophotometry (PerkinElmer Model 3030 equipped with a Model HGA400 graphite furnace). Upon determination of trace metals by ICP-AES, the matrix effects were addressed by preparing standards in solutions identical to the extracting solutions. In the case of graphite furnace atomic absorption spectrometry, palladium modifier was used for the determination of $\mathrm{Pb}$ (Shan and $\mathrm{Ni}, 1982$ ).

Analytical accuracy was assessed by decomposing and analysing five replicate samples of three certified reference materials using the procedures as described above. The results are summarized in Table 5. A good agreement of the data with the certified values was achieved overall and the precision of the determinations was good.
All reagents used were of analytical reagent grade or better.

\section{Results and discussion}

\subsection{Correlation between extractability of different extractants and plant uptake}

Evaluation of the data from soil extraction and plant metal analysis was based on correlation analysis. The range and mean concentrations of the analytical results are summarized in Table 6. Table 7 presents the correlation coefficients $(r)$ obtained between metals extracted by different extractants and metal concentrations in winter wheat (Triticum aestivum L.) and alfalfa (Medicago sativa $\mathrm{L}$.) grown on the experimental soils.

The variety of extractants and extraction procedures used in previous studies make it difficult to compare the results obtained by different workers or to assess the relative merits of various pro-

Table 6

Range and mean metal concentrations (in parentheses) of the individual soil extracts and of plants grown in the experimental soils $(n=10)$

\begin{tabular}{lllll}
\hline & $\mathrm{Ni}$ & $\mathrm{Co}$ & $\mathrm{Cu}$ & $\mathrm{Pb}$ \\
\hline DTPA & $0.24-0.94(0.51)$ & $0-0.27(0.18)$ & $0.66-4.83(2.32)$ & $0.85-8.03(3.17)$ \\
0.1 M HCl & $0.82-6.27(3.41)$ & $0.29-6.02(2.90)$ & $1.65-12.3(6.57)$ & $1.28-33.6(14.3)$ \\
Mehlich 3 & $1.20-5.97(3.43)$ & $0.63-8.39(4.09)$ & $2.83-19.1(9.22)$ & $1.37-16.5(8.74)$ \\
Alfalfa & $0.65-6.13(2.13)$ & $0.28-2.39(0.76)$ & $0.77-5.02(2.78)$ & $1.46-13.6(5.77)$ \\
Winter wheat & $0.29-2.92(1.43)$ & $0.34-2.56(1.01)$ & $0.58-6.93(2.57)$ & $1.32-13.0(5.48)$ \\
\hline
\end{tabular}

Values are the mean of triplicate determinations ( $\mu \mathrm{g} / \mathrm{g}$ dry wt.). 
Table 7

Correlation coefficients $(r)$ between contents of $\mathrm{Ni}, \mathrm{Co}, \mathrm{Cu}$ and $\mathrm{Pb}$ extracted by different extractants and concentrations of these metals in plants $(n=10)$

\begin{tabular}{llll}
\hline Extractant & Element & Alfalfa & Winter wheat \\
\hline Mehlich 3 & $\mathrm{Ni}$ & $0.644^{*}$ & 0.497 \\
& $\mathrm{Co}$ & 0.215 & -0.434 \\
& $\mathrm{Cu}$ & $0.635^{*}$ & $0.689^{*}$ \\
DTPA & $\mathrm{Pb}$ & 0.432 & $0.644^{*}$ \\
& $\mathrm{Ni}$ & $0.650^{*}$ & 0.347 \\
& $\mathrm{Co}$ & $-0.342^{*}$ & 0.289 \\
& $\mathrm{Cu}$ & $0.834^{* *}$ & $0.776^{* *}$ \\
$0.1 \mathrm{M} \mathrm{HCl}$ & $\mathrm{Pb}$ & $0.693^{*}$ & $0.891^{* *}$ \\
& $\mathrm{Ni}$ & $0.793^{* *}$ & $0.774^{* *}$ \\
& $\mathrm{Co}$ & $0.690^{*}$ & $0.811^{* *}$ \\
& $\mathrm{Cu}$ & 0.491 & 0.590 \\
& $\mathrm{~Pb}$ & $0.684^{*}$ & 0.395 \\
\hline
\end{tabular}

*Significant at 0.10 probability level.

**Significant at 0.050 probability level.

cedures. The data in this study indicate that the extractants showed remarkable differences in extracting soil metals. However, neither of the extractants alone was good enough for the evaluation of plant availability of all the metals under the conditions of this experiment. By comparison, winter wheat and alfalfa showed highly significant relationship with $\mathrm{Cu}$ extracted by Mehlich 3 and DTPA, but DTPA seemed to provide a better prediction of the plant availability of soil $\mathrm{Cu}$. A significant high correlation was also observed between $\mathrm{Ni}$ and $\mathrm{Co}$ extracted by $0.1 \mathrm{M} \mathrm{HCl}$ and their accumulation by both of the plants. In the case of $\mathrm{Pb}$, the quantity extracted by DTPA was significant by correlation with its levels in plants. It was therefore concluded that the best extractant might be $0.1 \mathrm{M} \mathrm{HCl}$ for $\mathrm{Ni}$ and $\mathrm{Co}$. For $\mathrm{Cu}$ and $\mathrm{Pb}$, the choice might be DTPA.

\subsection{Metal distribution among particle-size fractions}

Table 4 shows the distribution of the particlesize fractions. Silt was predominant among the portions of the particle sizes for all the samples. For soils 1, 4, and 6, the amount of clay was higher than that of sand. For soils 2, 3, 5, and 7, however, a higher percentage of sand and a lower percentage of clay were found.

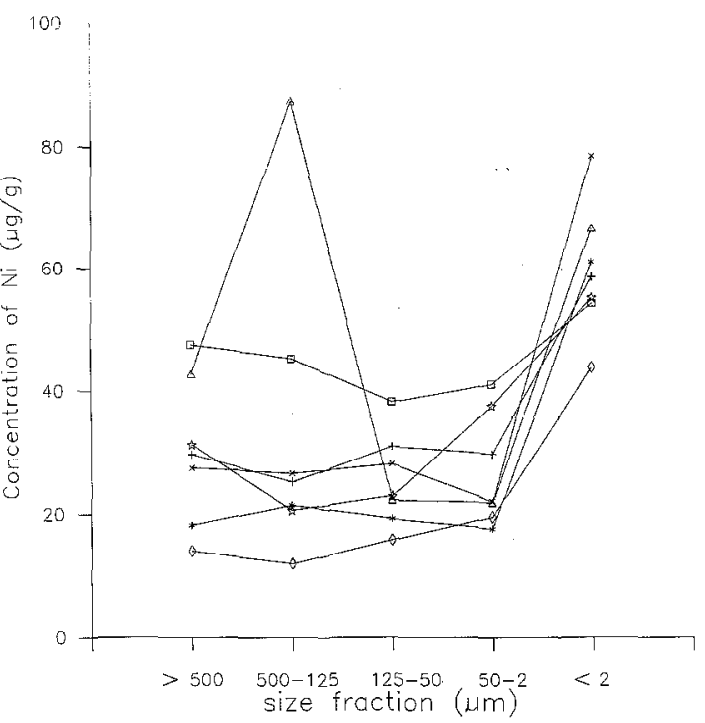

Fig. 1. Concentration distribution of $\mathrm{Ni}$ as a function of particle size in the size fractions of seven soils $(\Delta$ soil $1, \square$ soil $2, \diamond$ soil 3 , soil $4, \times$ soil $5, *$ soil $6,+$ soil 7 ).

The distributions of metals in the particle-size spectrum are shown in Figs. 1-4. It was obvious that metals were not homogeneously distributed over the various particle-size fractions, suggesting that particle size exercises a determining influence on the partitioning of heavy metals. Generally, the

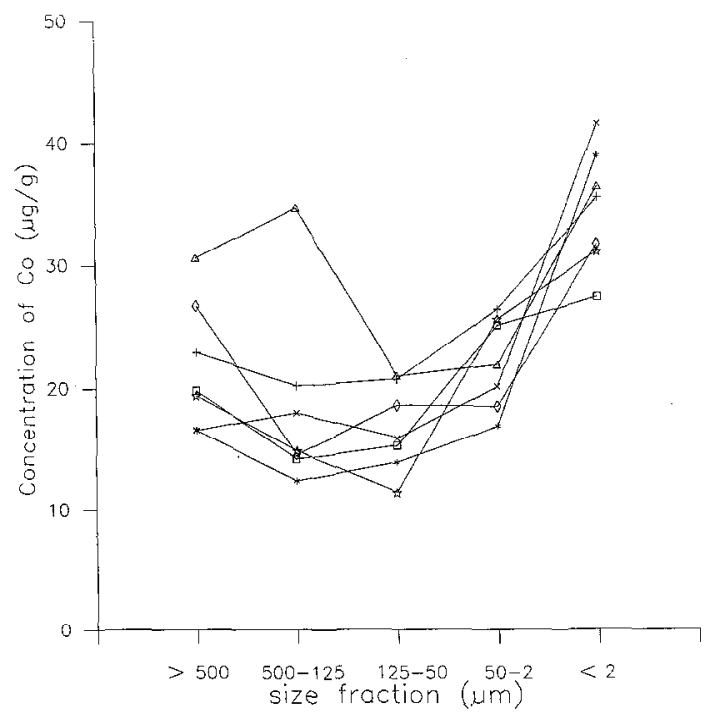

Fig. 2. Concentration distribution of $\mathrm{Co}$ as a function of particle size in the size fractions of seven soils $(\Delta$ soil $1, \square$ soil $2, \diamond$ soil 3 , soil $4, \times$ soil 5 , * soil $6,+$ soil 7 ). 


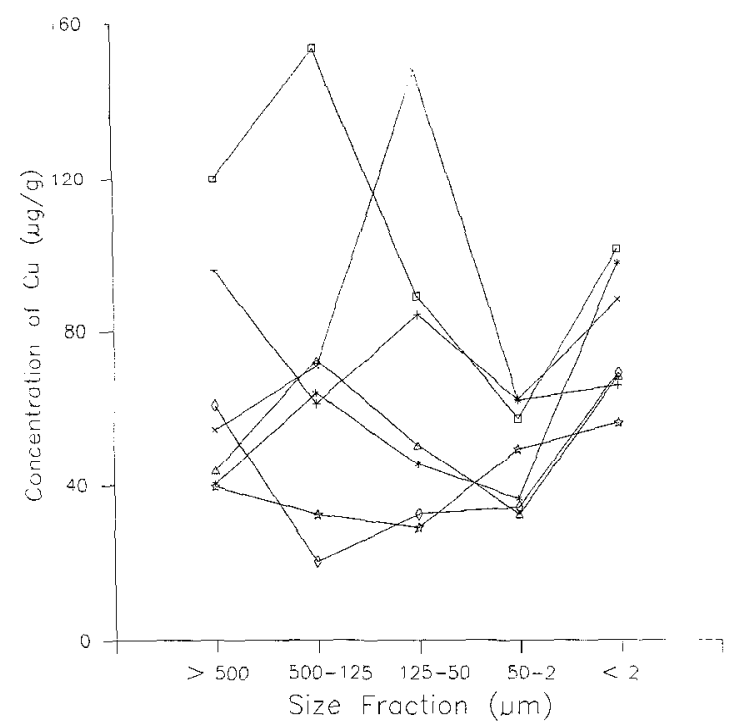

Fig. 3. Concentration distribution of $\mathrm{Cu}$ as a function of particle size in the size fractions of seven soils ( $\Delta$ soil $1, \square$ soil $2, \diamond$ soil 3, soil $4, \times$ soil 5 , * soil $6,+$ soil 7 ).

metals had bimodal distributions across the particle-size fractions, i.e. the metals tended to accumulate in the clay $(<2 \mu \mathrm{m})$ and one sand fraction $(>125 \mu \mathrm{m})$ of the soils.

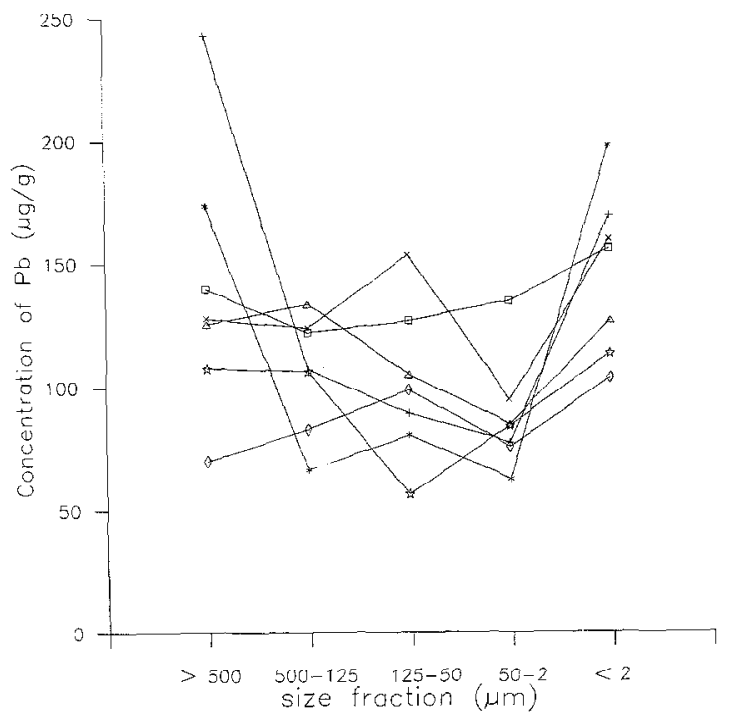

Fig. 4. Concentration distribution of $\mathrm{Pb}$ as a function of particle size in the size fractions of seven soils ( $\Delta$ soil $1, \square$ soil $2, \diamond$ soil 3 , soil $4, \times$ soil 5 , $*$ soil $6,+$ soil 7 ).
The distribution of heavy metals with particle size is primarily a function of mineral composition and amount of adsorption sites in each size fraction. The accumulation of metals in the clay fraction was in agreement with the findings reported by several workers, which were attributed to the high surface area and the presence of clay minerals, organic matter, Fe-Mn oxides and sulphides (Tiller, 1958; Förstner, 1980; Haque and Subramanian, 1982). These portions of metals appeared to be adsorbed as well as being present in the crystal lattice. It was reasonable to suggest that metal concentrations in the other fractions $(>2$ $\mu \mathrm{m})$ would decrease considering that these fractions were dominated by quartz components with low metal contents. This was to some extent evident for the sand fractions. In addition, increasing metal concentrations with decreasing particle sizes indicated that in this size range, the behaviour of the metals was governed by sorption processes. In another aspect, the increase of the metal portion in the sand fractions might be due to the presence of heavy minerals having a strong retention of heavy metals. It appeared, therefore, that these metals were in part associated with heavy minerals.

In general, concentration maxima in the clay and one of the sand fractions gave an indication that most of the metals studied were probably present in an adsorbed form on clay minerals or other clay materials, present in the crystal lattice of clay minerals or in the structure of heavy minerals.

\subsection{Correlations between extractable metal concen- trations from various particle-size fractions and plant uptake}

As described earlier, $\mathrm{HCl}$ and DTPA were most suitable for monitoring the whole soil for their availability of $\mathrm{Ni}, \mathrm{Co}$ and $\mathrm{Cu}, \mathrm{Pb}$, respectively, in relation to metal concentrations in winter wheat and in alfalfa. Therefore, they were also used for extracting the corresponding metals in the particlesize fractions of soil and the obtained extractable contents were considered to be significantly correlated with plant uptake.

Extractable metal concentrations as a function of particle size are given in Figs. 5-8, from which it is obvious that consistently high extractable con- 


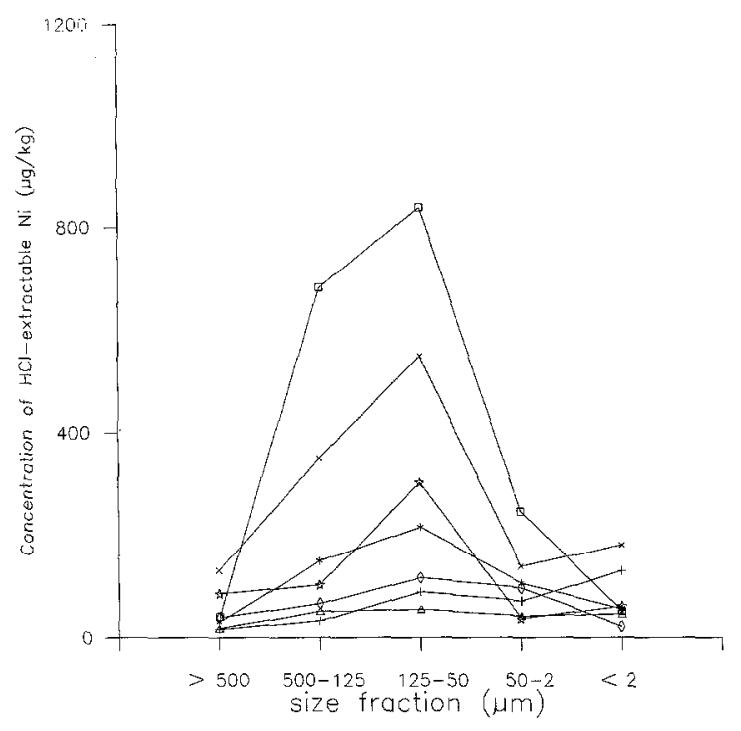

Fig. 5. Extractability of $\mathrm{Ni}$ by $0.1 \mathrm{M} \mathrm{HCl}$ as a function of particle size in the size fractions of seven soils $(\Delta$ soil $1, \square$ soil $2, \diamond$ soil 3, soil $4, \times$ soil 5 , soil $6,+$ soil 7 ).

centrations of metals could be found in the intermediate size fractions, i.e. fine sand fraction (50-125 $\mu \mathrm{m})$ for $\mathrm{Ni}, \mathrm{Cu}$, and $\mathrm{Pb}$, and medium sand fraction $(125-500 \mu \mathrm{m})$ for Co. Another

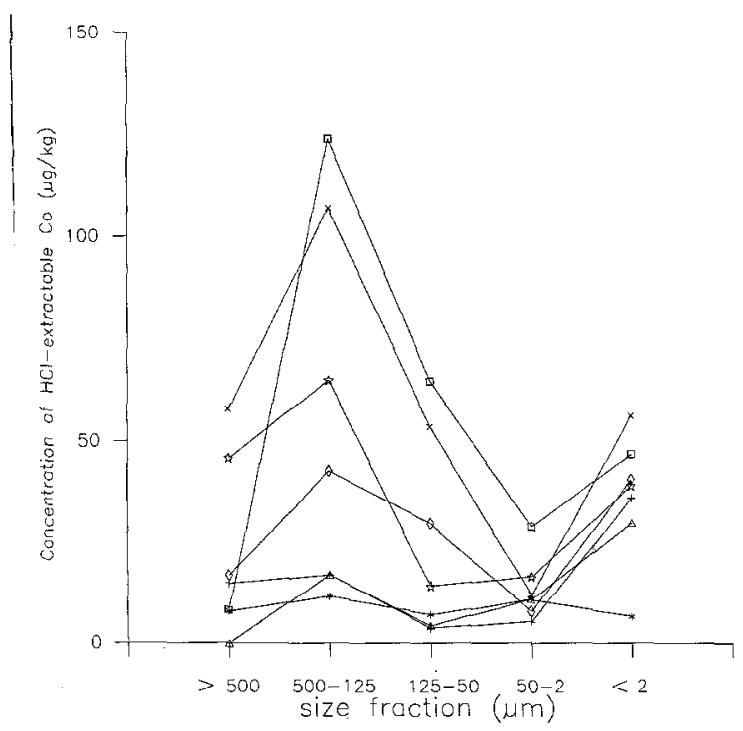

Fig. 6. Extractability of $\mathrm{Co}$ by $0.1 \mathrm{M} \mathrm{HCl}$ as a function of particle size in the size fractions of seven soils $(\Delta$ soil $1, \square$ soil $2, \diamond$ soil 3, soil $4, \times$ soil $5, *$ soil $6,+$ soil 7 ).

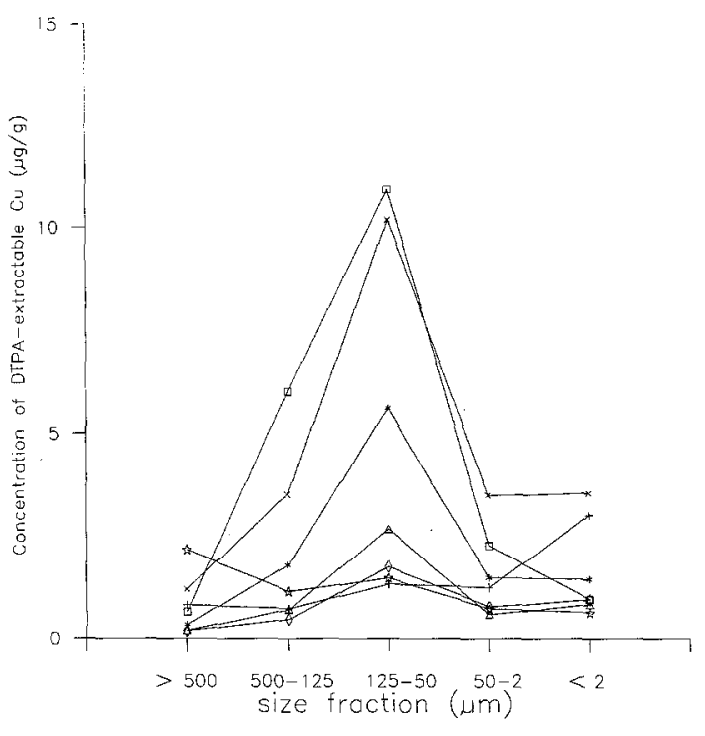

Fig. 7. Extractability of $\mathrm{Cu}$ by DTPA as a function of particle size in the size fractions of seven soils ( $\Delta$ soil $1, \square$ soil $2, \Delta$ soil 3 , soil $4, \times$ soil 5 , * soil $6,+$ soil 7 ).

characteristic feature for almost all samples was that the concentrations of $\mathrm{Co}$ and $\mathrm{Pb}$ differ from those of $\mathrm{Ni}$ and $\mathrm{Cu}$ by having another high value in the clay fraction $(<2 \mu \mathrm{m})$. It was interesting to

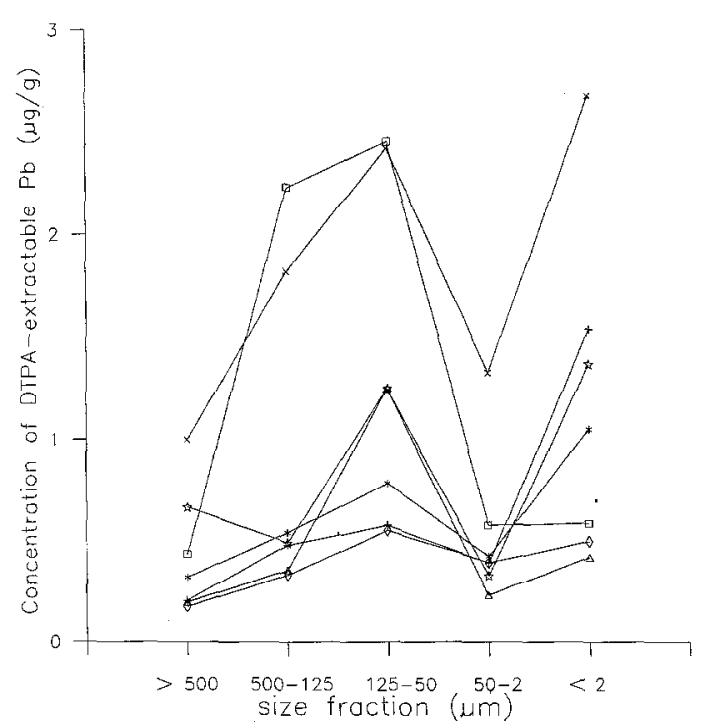

Fig. 8. Extractability of $\mathrm{Pb}$ by DTPA as a function of particle size in the size fractions of seven soils $(\Delta$ soil $1, \square$ soil $2, \Delta$ soil 3, soil $4, \times$ soil 5 , * soil 6 , + soil 7 ). 
note that the extractability of a specific metal by $\mathrm{HCl}$ or DTPA was similar for all the samples. This occurred despite a slight difference of enrichment in different size fractions between soil samples (Figs. 1-4).

It is difficult to precisely quantify this extraction behaviour because the mechanisms and energetics of metal-fraction interactions are not known with certainty. There is not a single mechanism responsible for the amount of metals extracted from different particle-size fractions, but the activity of metal ions in the fraction and the ability of the fraction to replenish those ions may be involved.
Both factors are important in determining the extractability of metals. The high extractability of metals from the fine/medium sand fraction seemed to be adversely related to the low binding strength of these fractions for such metals in competition with the extractant. Although all the metals were found to be enriched in the clay fraction, the extractable behaviour of $\mathrm{Co}$ and $\mathrm{Pb}$ differed from that of $\mathrm{Ni}$ and $\mathrm{Cu}$ by being more susceptible to extraction. The high extractable amount of $\mathrm{Co}$ and $\mathrm{Pb}$ from clay is probably owing to their high contents in adsorbed form which was easier to be extracted than those in the crystal lattice. By com-

Table 8

Relative contribution of different size fractions to the extractable metal concentrations (\%)

\begin{tabular}{|c|c|c|c|c|c|c|}
\hline \multirow[t]{2}{*}{ Sample No. } & \multirow[t]{2}{*}{ Metal } & \multicolumn{5}{|c|}{ Particle-size fraction } \\
\hline & & $\begin{array}{l}\text { Coarse sand } \\
(>500 \mu \mathrm{m})\end{array}$ & $\begin{array}{l}\text { Medium sand } \\
(125-500 \mu \mathrm{m})\end{array}$ & $\begin{array}{l}\text { Fine sand } \\
(50-125 \mu \mathrm{m})\end{array}$ & Silt $(2-50 \mu \mathrm{m})$ & Clay $(<2 \mu \mathrm{m})$ \\
\hline \multirow[t]{4}{*}{ Soil 1} & $\mathrm{Ni}$ & 0.78 & 2.41 & 2.43 & 73.33 & 21.06 \\
\hline & Co & 0 & 2.39 & 0.54 & 56.20 & 40.87 \\
\hline & $\mathrm{Cu}$ & 0.53 & 2.14 & 7.48 & 65.54 & 24.32 \\
\hline & $\mathrm{Pb}$ & 1.24 & 2.48 & 8.08 & 59.64 & 28.57 \\
\hline \multirow[t]{4}{*}{ Soil 2} & $\mathrm{Ni}$ & 3.10 & 24.56 & 20.45 & 49.28 & 2.61 \\
\hline & $\mathrm{Co}$ & 4.15 & 30.21 & 10.66 & 38.99 & 16.00 \\
\hline & $\mathrm{Cu}$ & 4.81 & 20.91 & 25.73 & 43.84 & 4.70 \\
\hline & $\mathrm{Pb}$ & 10.38 & 25.23 & 18.78 & 36.25 & 9.35 \\
\hline \multirow[t]{4}{*}{ Soil 3} & $\mathrm{Ni}$ & 4.42 & 11.75 & 12.74 & 67.96 & 3.13 \\
\hline & Co & 7.93 & 31.34 & 13.41 & 22.55 & 24.78 \\
\hline & $\mathrm{Cu}$ & 2.17 & 8.38 & 19.57 & 55.58 & 14.31 \\
\hline & $\mathrm{Pb}$ & 4.09 & 12.04 & 12.42 & 56.29 & 15.16 \\
\hline \multirow[t]{4}{*}{ Soil 4} & $\mathrm{Ni}$ & 6.24 & 6.25 & 24.49 & 38.37 & 24.65 \\
\hline & Co & 7.47 & 6.51 & 9.38 & 39.63 & 37.01 \\
\hline & $\mathrm{Cu}$ & 2.92 & 4.54 & 27.28 & 48.61 & 16.65 \\
\hline & $\mathrm{Pb}$ & 1.08 & 2.32 & 27.58 & 26.26 & 42.76 \\
\hline \multirow[t]{4}{*}{ Soil 5} & $\mathrm{Ni}$ & 1.21 & 4.54 & 25.65 & 56.88 & 11.72 \\
\hline & $\mathrm{Co}$ & 4.10 & 10.75 & 19.41 & 37.54 & 28.21 \\
\hline & $\mathrm{Cu}$ & 0.51 & 2.10 & 21.83 & 65.04 & 10.53 \\
\hline & $\mathrm{Pb}$ & 1.07 & 2.76 & 13.24 & 62.72 & 20.22 \\
\hline \multirow[t]{4}{*}{ Soil 6} & $\mathrm{Ni}$ & 0.36 & 1.44 & 7.71 & 63.28 & 27.20 \\
\hline & $\mathrm{Co}$ & 0.92 & 1.10 & 2.47 & 63.17 & 32.34 \\
\hline & $\mathrm{Cu}$ & 0.22 & 0.95 & 10.90 & 48.50 & 39.44 \\
\hline & $\mathrm{Pb}$ & 0.47 & 0.65 & 3.46 & 31.09 & 64.33 \\
\hline \multirow[t]{4}{*}{ Soil 7} & $\mathrm{Ni}$ & 2.11 & 6.69 & 18.71 & 55.60 & 16.89 \\
\hline & Co & 12.93 & 23.22 & 5.14 & 27.51 & 31.21 \\
\hline & $\mathrm{Cu}$ & 5.63 & 7.91 & 14.59 & 51.41 & 20.45 \\
\hline & $\mathrm{Pb}$ & 3.66 & 13.60 & 13.78 & 41.71 & 27.25 \\
\hline \multirow[t]{4}{*}{ Average } & $\mathbf{N i}$ & 2.60 & 8.23 & 16.03 & 57.81 & 15.32 \\
\hline & $\mathrm{Co}$ & 5.36 & 15.07 & 8.72 & 40.80 & 30.06 \\
\hline & $\mathrm{Cu}$ & 2.40 & 6.70 & 18.20 & 54.07 & 18.63 \\
\hline & $\mathrm{Pb}$ & 3.14 & 8.44 & 13.91 & 44.85 & 29.66 \\
\hline
\end{tabular}


parison, $\mathrm{Ni}$ and $\mathrm{Cu}$ seemed to be preferentially bound to the clay fraction as a result of competition between the extractant and clay. It was also evident that there was a strong retention of all the metals by the heavy minerals in the coarse/medium sand fractions, suggesting that metals present in the structure of heavy minerals were less available than an equivalent concentration in the other fractions of soil.

The relative importance of the size fractions in controlling heavy metal availability was evaluated by taking into account the joint effect of their relative abundance in soil (Table 4) and their extractable metal contents (Figs. 5-8). This was achieved by calculating the product of the two factors. The results are given in Table 8. Although the percent distribution of each size fraction varied considerably among samples, a common trend could be observed. The data averaged over all the soils indicated that silt was the major fraction contributing to metal extractability (on average, $\mathrm{Ni}$ $57.81 \%$, Co $40.80 \%$, Cu $54.07 \%$, Pb $44.85 \%$ ). This could be because of the simple predominance of silt in all soils (Table 3), although the extractable metal contents from silt were relatively low. Except for $\mathrm{Ni}$, clay was the next dominant fraction responsible for metal extractability. This was more evident for $\mathrm{Co}$ (average $30.06 \%$ ) and $\mathrm{Pb}$ (average $29.66 \%$ ). One reason for this behaviour was that the clay portion in all the soils was not low. In addition, the high percentage of clay $\mathrm{Co}$ and $\mathrm{Pb}$ was understandable when compared with their high extractability from clay (Figs. 6 and 8). A significant contribution from fine sand fraction was also found for $\mathrm{Ni}, \mathrm{Cu}$ and $\mathrm{Pb}$; while more extractable Co came from the medium sand than the fine sand. This result is in good agreement with the extractable pattern for this metal as described earlier. By comparison, the contribution from the coarse sand fraction, averaging between $2.40-5.36 \%$, became negligible, suggesting that very small amounts of plant available metals were derived from this fraction.

Even though the suitability of chemical extractions for predicting metal availability has been ascertained by correlation analysis in relation to metal contents in plants, the extraction method does not provide a direct and precise measure of metal uptake to plants. Furthermore, plant-related processes and interactions among the size fractions have been largely ignored. However, the results of this study can be helpful in predicting the relative portion which each size fraction contributes to metal availability.

\section{Conclusion}

The metals appeared to have bimodal distributions in the clay fraction and one sand fraction. Extraction data indicated that greater extractability existed in the fine sand fraction for $\mathrm{Ni}, \mathrm{Cu}$, and $\mathrm{Pb}$, and in the medium sand fraction for Co. For $\mathrm{Co}$ and $\mathrm{Pb}$, high extractable contents were also found in the clay fraction. Considering the relative abundance of the different size fractions, the silt fraction, based on its concentration advantage, became the dominant fraction responsible for metal availability. Clay and fine sand represented the next dominant fractions for $\mathrm{Ni}, \mathrm{Cu}$ and $\mathrm{Pb}$. For Co, however, the second dominant fraction was clay followed by the medium sand fraction.

Compared with previous studies on extraction of the whole soil, the present investigation provides more precise data and a better indication of metal availability from the various particle-size fractions of soil. Particle-size effects found in this study could present a good correction for a mutual comparison of metal extraction data of the whole soil. This investigation has demonstrated the importance of soil texture in controlling metal availability to plants. Although this paper is a preliminary one, further studies should ultimately lead to a better understanding of the soil chemistry of heavy metals and to the development of improved techniques for measuring metal availability from soil.

\section{Acknowledgement}

This work was supported by the National Natural Science Foundation of China and the State Key Laboratory of Environmental Aquatic Chemistry.

\section{References}

Arendt, F., M. Hinsenveld and W. Van Den Brink (Ed.), 1990. Contaminated Soil '90, Vol. 3. Kluwer, Dordrecht. 
Cottenie, A., 1981. In: W.H.O. Ernst (Ed.), Heavy Metals in the Environment. CEP Consultants Ltd., Edinburgh, UK, $167 \mathrm{pp}$.

Davies, B.E., 1992. Inter-relationships between soil properties and the uptake of cadmium, copper, lead and zinc from contaminated soils by radish (Raphanus sativus L.). Water Air Soil Pollut., 63: 331-342.

Förstner, U., 1980. Trace metal analysis of polluted sediments, Part 1. Assessment of sources and intensities. Environ. Technol. Lett., 1: 494-505.

Haq, A.U., T.E. Bates and Y.K. Soon, 1980. Comparison of extractants for plant-available zinc, cadmium, nickel, and copper in contaminated soils. Soil Sci. Soc. Am. J., 44: 772-777.

Haque, M.A. and V. Subramanian, 1982. $\mathrm{Cu}, \mathrm{Pb}$ and $\mathrm{Zn}$ pollution of soil environment. CRC Crit. Rev. Environ. Contr., 12: $13-90$.

Iyengar, S.S., D.C. Martens and W.P. Miller, 1981. Distributions and plant availability of soil zinc fractions. Soil Sci. Soc. Am. J., 45: 735-739.

Lake, D.L. and J.N. Lester, 1984. Fractionation, characterization and speciation of heavy metals in sewage sludge and sludge-amended soils: a review. J. Environ. Qual., 13: $175-183$.

Lindsay, W.L. and W.A. Norvell, 1978. Development of a DTPA soil test for zinc, iron, manganese and copper. Soil Sci. Soc. Am. J., 42: 421-428.

Martens, D.C., 1968. Plant availability of extractable boron, copper, and zinc as related to selected soil properties. Soil Sci., 106: 23-28.

Mehlich, A., 1984. Mehlich 3 soil test extractant: a modification of Mehlich 2 extractant. Commun. Soil Sci. Plant Anal., 15: 1409-1416.

Nelson, D.W. and L.E. Sommers, 1982. Total carbon, organic carbon, and organic matter. In: A.L. Page et al. (Eds), Methods of Soil Analysis, part 2. Agron. Monogr. 9. ASA and SSSA, Madison, WI, 2nd edn., pp. 539-579.
Nriagu, J.0., 1991. Human influence on the global cycling of trace metals. In J.G. Farmer (Ed.), Heavy Metals in the Environment, Vol. 1. CEP Consultants Ltd., Edinburgh, UK, pp. 1-5.

Rhoades, J.D., 1982. Cation-exchange capacity. In: A.L. Page et al. (Eds), Methods of Soil Analysis, part 2. Agron. Monogr. 9. ASA and SSSA, Madison, WI, 2nd edn., pp. 149-158.

Sauerbeck, D.R. and A. Hein, 1991. The nickel uptake from different soils and its prediction by chemical extractions. Water Air Soil Pollut., 57-58: 861-871.

Shan, X.-Q. and Z.-M. Ni, 1982. Matrix modification for the determination of lead in urine by graphite furnace atomic absorption spectrometry. Can. J. Spectrosc., 27: 75-81.

Singh, B.R. and R.P. Narwal, 1984. Plant availability of heavy metals in a sludge-treated soil. II. Metal extractability compared with plant metal uptake. J. Environ. Qual., 13: 344-349.

Sims, J.T. and J.S. Kline, 1991. Chemical fractionation and plant uptake of heavy metals in soils amended with cocomposed sewage sludge. J. Environ. Qual., 20: 387-395.

Soon, Y.K. and T.E. Bates, 1982. Chemical pools of cadmium, nickel and zinc in polluted soils and some preliminary indications of their availability to plants. J. Soil Sci., 33: 477-488.

Sterritt, R.M. and J.N. Lester, 1980. The value of sewage sludge to agriculture and effects of the agricultural use of sludges contaminated with toxic elements: a review. Sci. Total Environ., 16: 55-90.

Taylor, R.W., I.O. Ibeabuchi, K.R. Sistani and J.W. Shuford, 1993. Heavy metal concentration in forage grasses and extractability from some acid mine spoils. Water Air Soil Pollut., 68: 363-372.

Tiller, K.G., 1958. The geochemistry of basaltic materials and associated soils of southeastern South Australia. J. Soil Sci., 9: 225-241. 